\section{Commentary: Using hepatitis C-infected hearts in the United States - an idea gone viral-ish}

\author{
Ashish S. Shah, MD
}

Most of us in the field of heart transplantation will look at the use of hepatitis C-positive donors as a small but important achievement of the 21 st century. First is the discovery and rapid dissemination of direct-acting antivirals that have revolutionized hepatitis $\mathrm{C}$ treatment and management. The second, perhaps quieter achievement is the repurposing of this discovery to transmute an unusable heart to useable. Thanks to rapid transmission of the drug discovery and thoughtful clinicians having in-person discussions, we now have a viable pool of hearts. The current study appears to be an early report card on how this idea has been spreading in the United States. ${ }^{1} \mathrm{Li}$ and colleagues ${ }^{1}$ used the United Network for Organ Sharing dataset to explore trends in hepatitis $\mathrm{C}$-infected organ use with a focus on geography. They conclude that there are high adopters and not so high adopters. There are regions that have programs that use a lot of these organs and those that do not. There are few interesting findings, such as the significant use of hepatitis $\mathrm{C}$ viremic donors in low clinical priority patients. There is also information regarding viral serocoversion, suggesting that the majority of patients are initially cured. However, the United Network for Organ Sharing dataset was not designed to explore preoperative decision making or postoperative complications in meaningful ways. Although centers may be concerned about using these hearts, those that do not seem to realize it is a way to get people transplanted within the current imperfect US allocation scheme. This study is as much a psychological report card on the viral spread of an

\footnotetext{
From the Department of Cardiac Surgery, Vanderbilt University Medical Center, Vanderbilt Medical Center East, Nashville, Tenn. Disclosures: The author reported no conflicts of interest.

The Journal policy requires editors and reviewers to disclose conflicts of interest and to decline handling or reviewing manuscripts for which they may have a conflict of interest. The editors and reviewers of this article have no conflicts of interest.

Received for publication Sept 23, 2020; revisions received Sept 23, 2020; accepted for publication Sept 24, 2020; available ahead of print Oct 6, 2020.

Address for reprints: Ashish S. Shah, MD, Department of Cardiac Surgery, Vanderbilt University Medical Center, Vanderbilt Medical Center East, 1215 21st Ave S, Suite 5025, Nashville, TN 37232 (E-mail: ashish.s.shah@vanderbilt.edu).

J Thorac Cardiovasc Surg 2022;163:1889

$0022-5223 / \$ 36.00$

Copyright (c) 2020 by The American Association for Thoracic Surgery

https://doi.org/10.1016/j.jtcvs.2020.09.108
}

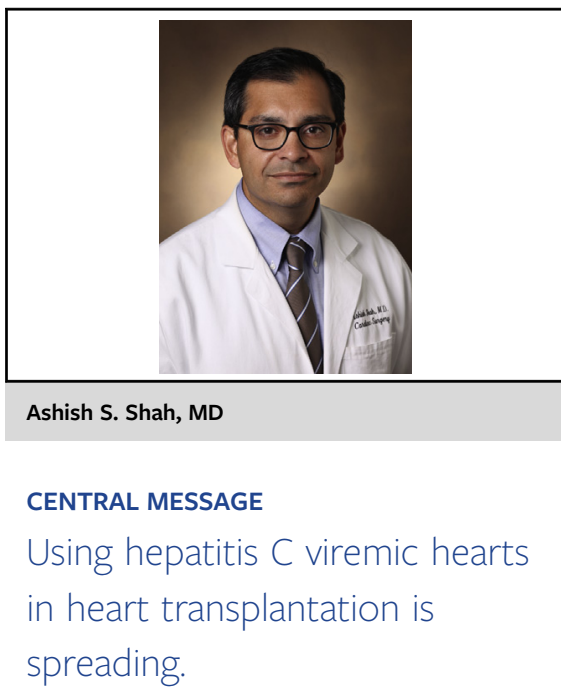

idea in a unique field, where time is really the key variable. And although the desperation of courageous patients and clinicians has driven a few centers to adopt this concept, many remain on the sidelines. The authors touch on this, but ultimately fear may be at the core of slow widespread adoption. Institutional anxieties over long-term consequences and short-term costs are certainly rational barriers. However legitimate, are these concerns more important than the well-being of patients in chronic heart failure? Heart transplantation itself had enormous and viral enthusiasm in 1967 and 1968, only to be met with intense criticism and vilification of the pioneering transplant teams by 1971. Will the miracle of hepatitis $C$ hearts face the same fate? Time will tell. Time that many patients do not have.

\section{Reference}

1. Li SS, Osho A, Moonsamy P, D’Alessandro DA, Lewis GD, Villavicencio MA et al. Trends in the use of hepatitis $\mathrm{C}$ viremic donor hearts. J Thorac Cardiovasc Surg. 2022;163:1873-85.e7. 